\title{
An expertise reversal effect of segmentation in learning from animated worked-out examples
}

Citation for published version (APA):

Spanjers, I. A. E., Wouters, P., van Gog, T., \& van Merrienboer, J. J. G. (2011). An expertise reversal effect of segmentation in learning from animated worked-out examples. Computers in Human Behavior, 27(1), 46-52. https://doi.org/10.1016/j.chb.2010.05.011

Document status and date:

Published: 01/01/2011

DOI:

10.1016/j.chb.2010.05.011

Document Version:

Publisher's PDF, also known as Version of record

Document license:

Taverne

\section{Please check the document version of this publication:}

- A submitted manuscript is the version of the article upon submission and before peer-review. There can be important differences between the submitted version and the official published version of record.

People interested in the research are advised to contact the author for the final version of the publication, or visit the DOI to the publisher's website.

- The final author version and the galley proof are versions of the publication after peer review.

- The final published version features the final layout of the paper including the volume, issue and page numbers.

Link to publication

\footnotetext{
General rights rights.

- You may freely distribute the URL identifying the publication in the public portal. please follow below link for the End User Agreement:

www.umlib.nl/taverne-license

Take down policy

If you believe that this document breaches copyright please contact us at:

repository@maastrichtuniversity.nl

providing details and we will investigate your claim.
}

Copyright and moral rights for the publications made accessible in the public portal are retained by the authors and/or other copyright owners and it is a condition of accessing publications that users recognise and abide by the legal requirements associated with these

- Users may download and print one copy of any publication from the public portal for the purpose of private study or research.

- You may not further distribute the material or use it for any profit-making activity or commercial gain

If the publication is distributed under the terms of Article $25 \mathrm{fa}$ of the Dutch Copyright Act, indicated by the "Taverne" license above, 


\title{
An expertise reversal effect of segmentation in learning from animated worked-out examples के
}

\author{
Ingrid A.E. Spanjers ${ }^{\mathrm{a}, \mathrm{b}, *}$, Pieter Wouters ${ }^{c}$, Tamara van Gog ${ }^{\mathrm{a}, \mathrm{d}}$, Jeroen J.G. van Merriënboer ${ }^{\mathrm{a}, \mathrm{b}}$ \\ ${ }^{a}$ Centre for Learning Sciences and Technologies \& Netherlands Laboratory for Lifelong Learning, Open Universiteit in The Netherlands, Heerlen, The Netherlands \\ ${ }^{\mathrm{b}}$ Department of Educational Development and Research \& School of Health Professions Education, Maastricht University, The Netherlands \\ ${ }^{\mathrm{c}}$ Institute of Information and Computing Sciences, Utrecht University, The Netherlands \\ ${ }^{\mathrm{d}}$ Institute of Psychology, Erasmus University Rotterdam, The Netherlands
}

\section{A R T I C L E I N F O}

\section{Article history:}

Available online 31 May 2010

\section{Keywords:}

Instructional animations

Cognitive load

Segmentation

Expertise reversal effect

Multimedia learning

\begin{abstract}
A B S T R A C T
Many animations impose a high cognitive load due to the transience of information, which often hampers learning. Segmentation, that is presenting animations in pieces (i.e., segments), has been proposed as a means to reduce this high cognitive load. The expertise reversal effect shows, however, that design measures that have a positive effect on cognitive load and learning for students with lower levels of prior knowledge, might not be effective, or might even have a negative effect on cognitive load and learning for students with higher levels of prior knowledge. This experiment with animated worked-out examples showed an expertise reversal effect of segmentation: segmented animations were more efficient than continuous animations (i.e., equal test performance with lower investment of mental effort during learning) for students with lower levels of prior knowledge, but not for students with higher levels of prior knowledge.
\end{abstract}

(c) 2010 Elsevier Ltd. All rights reserved.

\section{Introduction}

Animations are increasingly used in instructional material to visualize natural processes (e.g., Long Term Potentiation occurring in synapses: Amadieu, Mariné, \& Laimay, 2011; the formation of lightning; Schmidt-Weigand \& Scheiter, 2011) or mechanical systems (e.g., a car's braking system; Mayer, Hegarty, Mayer, \& Campbell, 2005), or to demonstrate and explain problem solving methods (e.g., animated worked-out examples demonstrating how to solve probability calculation problems; Wouters, Paas, \& Van Merriënboer, 2009, 2010). This is probably done because animations are considered to be attractive for students (e.g., Chandler, 2009; Tversky, Heiser, Mackenzie, Lozano, \& Morrison, 2008). However, they are expensive to develop, and research has shown that they are not always more effective for learning than static pictures (e.g., Hegarty, Kriz, \& Cate, 2003; Mayer et al., 2005; Tversky, Morrison, \& Betrancourt, 2002), although there seem to be certain types of tasks for which animations are more effective, which often

\footnotetext{
is This work was funded by The Netherlands Organization for Scientific Research (NWO; project 400-07-017).

* Corresponding author. Address: Department of Educational Development and Research, Maastricht University, P.O. Box 616, Maastricht, 6200 MD, The Netherlands. Tel.: +31 43388 5722; fax: +31 433885779 .

E-mail address: i.spanjers@EDUC.unimaas.nl (I.A.E. Spanjers).
}

involve animated examples demonstrating (psycho)motor procedures (Höffler \& Leutner, 2007; see also Van Gog, Paas, Marcus, Ayres, \& Sweller, 2009).

It has been argued that the efficiency and effectiveness of animations can be improved by design measures that take cognitive load into account (Ayres \& Paas, 2007). A number of measures has been proposed to improve the efficiency and effectiveness of animations by reducing extraneous or ineffective cognitive load and increasing germane or effective cognitive load. These include visuospatial cueing, that is, visually highlighting one or more elements in animations (e.g., De Koning, Tabbers, Rikers, \& Paas, 2007), pre-training, that is, presenting components of the instructional material before the animations (e.g., Mayer, Mathias, \& Wetzell, 2002), or segmentation, that is, showing animations in pieces or segments (e.g., Mayer \& Chandler, 2001). However, research on the expertise reversal effect (e.g., Wetzels, Kester, \& Van Merriënboer, 2011; see for a review Kalyuga, Ayres, Chandler, \& Sweller, 2003) has shown that measures that have a positive effect on efficiency and effectiveness for students with lower levels of prior knowledge might have no, or even a negative, effect on efficiency and effectiveness for students with higher levels of prior knowledge. This study investigates whether an expertise reversal effect of segmentation occurs with animated worked-out examples on probability calculation (see Wouters et al., 2009, 2010). 


\subsection{Effects of segmentation and learner expertise}

To learn from animations, information needs to be maintained and processed in working memory. Working memory has a limited capacity (Baddeley, 2003) and has time constraints (Barrouillet \& Camos, 2007), as a consequence of which only two or three information elements can be simultaneously processed. Cognitive Load Theory (Sweller, Van Merriënboer, \& Paas, 1998; Van Merriënboer \& Sweller, 2005) distinguishes between three additive types of cognitive load imposed on working memory by maintaining and processing information: Extraneous (i.e., ineffective) and germane (i.e., effective) cognitive load imposed by the design of instructional materials, and intrinsic cognitive load, imposed by the number of novel, interacting information elements in the material that have to be simultaneously processed. Intrinsic load is also influenced by students' level of expertise: When students gain knowledge in a domain, they construct cognitive schemas by combining information elements and those schemas can be handled in working memory as single information elements. Therefore, the same animations impose less intrinsic load for students with higher levels of prior knowledge than for students with lower levels of prior knowledge. Consequently, students with higher levels of prior knowledge have more resources left to deal with processes that impose extraneous load (e.g., linking related elements from physically separated parts of the display) and to be engaged in processes that induce germane load (e.g., studying different problem variants) than students with lower levels of prior knowledge (Sweller et al., 1998).

Due to the transience of information in animations (i.e., information presented at one moment makes place for new information presented the next moment), learners need to maintain and process information, while simultaneously attending to new information (Mayer \& Moreno, 2003). Consequently, transience induces high extraneous load (Ayres \& Paas, 2007). Students with higher levels of prior knowledge are probably able to deal with this extraneous load, because the intrinsic load of the material is lower for them than for students with lower levels of prior knowledge. The high load imposed by transience, therefore, can be expected to mainly hinder students with lower levels of prior knowledge (cf. Kalyuga, 2008).

Segmentation has been proposed as a means to reduce the high load occurring due to the transience of animations (e.g., Ayres \& Paas, 2007; Mayer \& Moreno, 2003; Schnotz \& Lowe, 2008). In most segmentation studies, pauses between the segments are made, which gives students time to process the information presented in the previous segment without having to attend to new incoming information (Mayer \& Chandler, 2001; Mayer \& Moreno, 2003). In this way, segmentation can support students in dealing with the complexity of the material presented in the animation.

In addition, segmentation breaks the animation down into meaningful pieces (Schnotz \& Lowe, 2008). Consequently, segmentation can be seen as a kind of cueing, but on a temporal rather than a visuospatial level. That is, whereas visuospatial cueing highlights one or more elements in the animation, segmentation can highlight the underlying structure of the depicted process/procedure by demarcating points in time, which could aid students' learning by making them aware of particular sub-steps and - possibly stimulating them to self-explain the goals of those sub-steps (cf. Catrambone, 1998).

However, as mentioned above, these beneficial effects of segmentation might mainly be relevant for students with lower levels of prior knowledge. When the information contained in an animation is (partly) familiar to students, they are able to deal with its transience (cf. Kalyuga, 2008). Therefore, segmentation might not be necessary or might even harm learning for students with higher levels of prior knowledge. Research on the expertise reversal effect has shown that measures to improve the efficiency and effectiveness of instructional material by providing additional guidance are often useful for students with lower levels of prior knowledge, but not for students with higher levels of prior knowledge, who do not need additional instructional guidance, and might even be bothered by it, because they would have to reconcile the guidance provided by their own schemas with the instructional guidance, which might induce extraneous load (Kalyuga et al., 2003). A study by Schnotz (2002) on simulations, provides preliminary support for the assumption that an expertise reversal effect might also occur with segmentation of animations. He found a positive effect of segmentation of a simulation for students with lower levels of prior knowledge, but no effect for students with higher levels of prior knowledge on one of the tests.

In sum, this study investigates whether an expertise reversal effect of segmentation arises in learning from animated worked-out examples on probability calculation (see Wouters et al., 2009, 2010). It is hypothesized that segmented, animated worked-out examples will lead to more effective and/or efficient learning processes, that is, equal/higher transfer test scores with lower/equal investment of mental effort during learning (Van Gog \& Paas, 2008) for students with lower levels of prior knowledge, but that with higher levels of prior knowledge the beneficial effects of segmentation will disappear, so that continuous, animated examples will be equally or more efficient than segmented ones for students with higher levels of prior knowledge.

\section{Method}

\subsection{Participants and design}

Participants were 76 Dutch secondary education students (53\% females; mean age $=16.16, S D=0.80$ ) attending the fourth or fifth year of senior general secondary education (total duration: 5 years) or pre-university education (total duration: 6 years). They were randomly assigned to either the segmented or the continuous, animated worked-out examples condition. Data from one participant had to be excluded due to too many missing values, which resulted in 37 students in the segmented and 38 in the continuous condition.

\subsection{Materials}

\subsubsection{Learning environment}

A computer-based learning environment developed in Flash MX (Macromedia., 2002) administered all parts of the experiment (prior knowledge test, animated worked-out examples, transfer tests). With the exception of the animated examples, all parts were learner-paced.

\subsubsection{Prior knowledge test}

A prior knowledge test consisting of four multiple-choice and eight open items about probability calculation (see Wouters et al., 2009, 2010) was used to measure students' prior knowledge. An example of an open item is: 'You are playing a game with some friends and it is your turn to throw a dice. If you throw sixes you win. What is the probability that you throw sixes?'. An example of a multiple-choice item is: 'You have a deck of cards from which you select four cards. You want to get an ace, king, queen, and jack - in this specific order. Does it matter whether you put back the selected cards before each new selection or not?', with answer options being (a) Yes, your chances increase when you put back the selected cards, (b) Yes, your chances decrease when you put back the selected cards, (c) No, your chances remain the same whether 
you put back the selected cards or not, or (d) This depends on the number of jokers in the deck of cards.

\subsubsection{Animated worked-out examples}

The learning phase consisted of eight animated worked-out examples on probability calculation (see Fig. 1), preceded by a short introduction in which information relevant for learning about probability calculation was given, like what randomisation is, what individual and complex events are, and how counting can be used in solving probability calculation problems. The introduction was the same for both groups, except for a part in which information about the animated examples was given.

The animated examples, which were computer-paced and had a duration of approximately $2 \mathrm{~min}$, demonstrated and explained how probability calculation problems dealing with complex events (i.e., involving more than one individual event) need to be solved. They included a pedagogical agent (a dolphin) and text spoken by a male voice with a neutral accent. The animated examples depicted four different types of problems, determined by the four combinations that can be made with two factors that are important for probability calculation: (1) relevance of order (relevant, irrelevant), and (2) replacement after drawing (yes, no). Two animated examples were shown for each problem type, and the first always had a cover story about helmets handed out on a mountain bike trip, whereas the cover story of the second varied per problem type. The order of the problem types was: order relevant/without replacement, order relevant/with replacement, order irrelevant/ without replacement and order irrelevant/with replacement. An example of a problem presented is: 'Together with your friend, you go on a 2-day mountain bike trip. Each day the instructor takes with him five helmets, which each have a different color: blue, green, yellow, red and silver. The helmets are distributed randomly, and are given back to the instructor at the end of the day. On both days you get a helmet first, and your friend second. What is the probability that on the first day, you will get the blue helmet and your friend will get the green helmet?'. Two methods for solving probability calculation problems were shown. The method of counting was shown if order was relevant in that problem and the method of individual events if order was irrelevant in that problem. The method of counting involves determining the number of possible outcomes and the number of correct outcomes. For example, if one wants to calculate the probability that one obtains a blue helmet out of five helmets on the first day of a mountain bike trip and a green one on the second day, one calculates that the number of possible outcomes is $5^{2}=25$ and determines that only one of those 25 outcomes is correct, so the probability is $1 / 25$. The method of individual events consists of determining the probability of individual events and multiplying those probabilities in order to calculate the probability of the complex event. In the example above, one could also have determined first that the probabilities for the individual events are $1 / 5$ and $1 / 5$ and subsequently calculate that the probability is $1 / 5 * 1 / 5=1 / 25$.

In the continuous condition each animated worked-out example was shown as one continuous stream of information. In the segmented condition each animated example was divided into segments with pauses of $2 \mathrm{~s}$ between them, during which the screen was slightly darkened. After the pauses, the animated examples continued automatically. The length of segments and the moment of the segment endings were determined together with three experts (one statistician and two math teachers) and were slightly adapted based on a pilot test. Depending on the problem type the number of segments varied between 5 and 7 . The first segment presented the problem statement. The second described whether order was relevant or not for this problem and the third whether the problem was about drawing with or without replacement. In the fourth and subsequent segments the method to solve the problem was chosen and the different steps of the method were demonstrated.

\subsubsection{Transfer tests}

The transfer tests consisted of eight open near transfer and four open far transfer items. The near transfer items had a similar
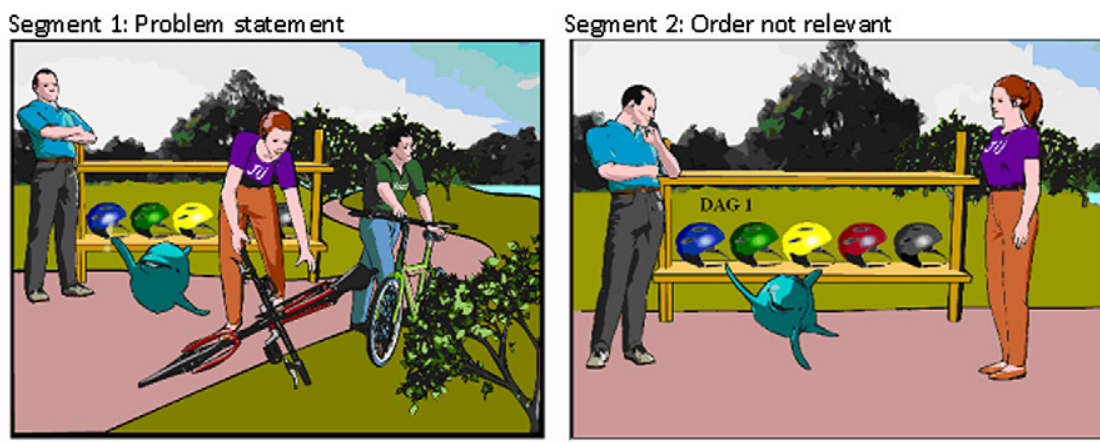

Segment 4: Method selection and probability for the $1^{\text {st }}$ individual event

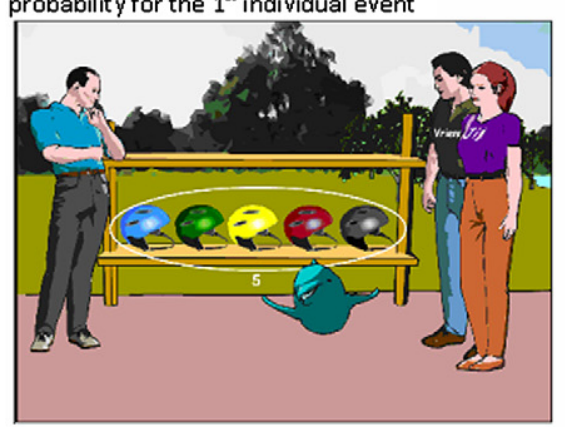

Segment 5: Probability for the $2^{\text {nd }}$ individual event

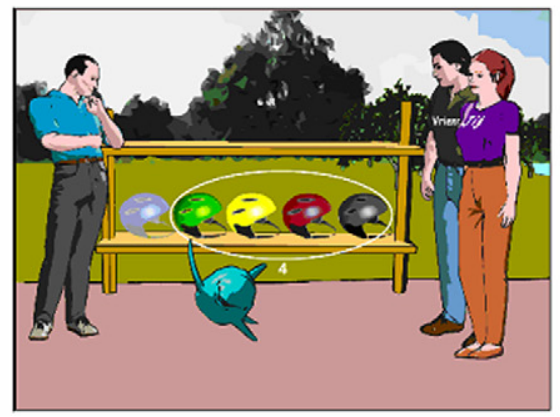

Segment 3: Drawing without replacement

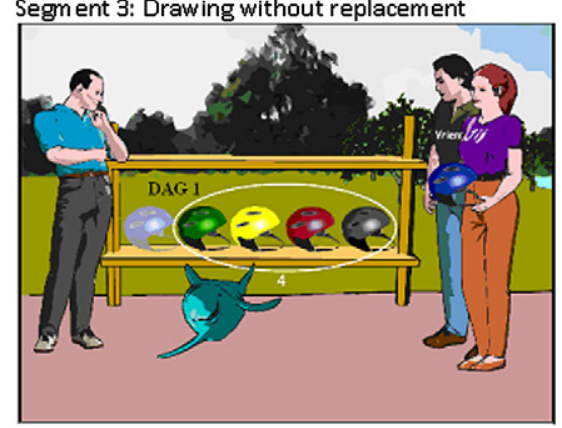

Segment 6: Probability com plex event

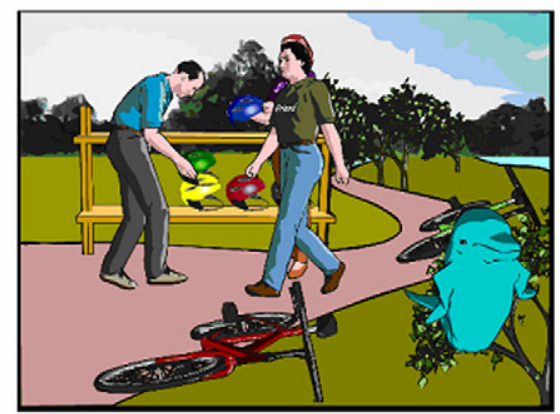

Fig. 1. Series of screen shots from one of the animated worked-out examples (text was spoken). 
structure to the problems presented in the animated examples (i.e., students could use the problem solving methods they had studied), but different cover stories (e.g., about concert tickets instead of helmets). The far transfer items consisted of problems with a different structure than those in the animated examples, so students had to adapt the problem solving methods. For example, some items required the students to combine the problem solving methods shown in the animated examples to solve problems consisting of two complex events: 'You are about to take an exam in order to determine the final mark for a subject. First, you have to perform two tasks, then a test consisting of eight multiple-choice questions. Two out of five possible tasks (A-E) will be randomly assigned to you. You have already practiced tasks D and E a month ago. Eight multiple-choice questions will be selected for you from a large pool of 100 different questions. You have made a test before with eight questions from this pool. What is the probability that you are assigned tasks D and E as well as the eight questions you have had before?'

\subsubsection{Mental effort}

Immediately after studying each animated example, students rated how much mental effort they invested in studying it on a 9-point subjective rating scale ranging from (1) very, very low mental effort to (9) very, very high mental effort (Paas, 1992).

\subsection{Procedure}

The experiment was conducted in computer rooms at the students' schools. It had a duration of approximately $1.5 \mathrm{~h}$. First, students could read what the purpose of the experiment was and of which parts it consisted. Subsequently, they indicated their gender and age. After that they completed the prior knowledge test. This test was followed by the introduction on probability calculation. At the end of this introduction information about the animated examples was given. With a continue button the students could proceed to the animated examples, using headsets to listen to the auditory information. After each animated example students rated their invested mental effort. Finally, students completed the transfer tests, after which they were debriefed and thanked for their participation.

\subsection{Scoring}

Test performance was scored by giving 1 point for a correct answer (i.e., max score prior knowledge: 12 , near transfer: 8 , far transfer: 4). No partial credit was given and computational errors were ignored (for more details on the scoring procedure, see Wouters et al., 2009, 2010). Efficiency on both the near and the far transfer test was calculated using the formula developed by Paas and Van Merriënboer (1993), but with test performance and mental effort invested in studying the animated examples (i.e., efficiency in terms of learning process, where a high efficiency denotes equal/low investment of effort during learning combined with high/equal performance on the test; see Van Gog \& Paas, 2008). In case of missing mental effort scores, these were replaced with the grand mean (see Paas \& Van Merriënboer, 1993).

\section{Results}

Table 1 shows the descriptive statistics for prior knowledge, near and far transfer test performance, mental effort, efficiency on the near and far transfer tests, and time on task for the prior knowledge, near, and far transfer tests. Regression analyses on near and far transfer test performance, mental effort, and efficiency were executed with prior knowledge, condition and the interaction
Table 1

Descriptive statistics for prior knowledge and the outcome variables for both conditions.

\begin{tabular}{|c|c|c|c|c|}
\hline \multirow[t]{3}{*}{ Variable } & \multicolumn{4}{|c|}{ Condition } \\
\hline & \multicolumn{2}{|c|}{ Continuous } & \multicolumn{2}{|c|}{ Segmented } \\
\hline & $M$ & $S D$ & $M$ & $S D$ \\
\hline Prior knowledge (0-12) & 5.13 & 1.55 & 4.92 & 1.99 \\
\hline Time on task (in s) & 641 & 278 & 586 & 275 \\
\hline \multicolumn{5}{|l|}{ Instruction } \\
\hline Mental effort (1-9) & 2.53 & 1.56 & 2.35 & 1.11 \\
\hline \multicolumn{5}{|l|}{ Near transfer test } \\
\hline Performance (0-8) & 2.24 & 1.85 & 2.86 & 1.92 \\
\hline Efficiency & -0.16 & 1.28 & 0.17 & 1.04 \\
\hline Time on task (in s) & 464 & 225 & 476 & 213 \\
\hline \multicolumn{5}{|l|}{ Far transfer test } \\
\hline Performance (0-4) & 0.37 & 0.71 & 0.46 & 0.61 \\
\hline Efficiency & -0.10 & 1.28 & 0.10 & 0.86 \\
\hline Time on task (in s) & 310 & 200 & 329 & 174 \\
\hline
\end{tabular}

term prior knowledge $*$ condition entered simultaneously as predictors (significance level .05). To avoid problems with multicollinearity, prior knowledge was centered (Aiken \& West, 1991). Condition was coded as 0 for the continuous condition and 1 for the segmented condition in the model used to examine the presence of an interaction between prior knowledge and condition. Follow-up tests on significant interactions were conducted by examining the specific impact of prior knowledge in each of the conditions separately. This was done through testing the regression coefficient for prior knowledge in the continuous condition with condition coded as continuous $=0$ and segmented $=1$, and in the segmented condition with condition coded as continuous $=1$ and segmented $=0$. In addition, the interactions were further tested by examining the significance of the difference between the regression lines for students with lower and higher prior knowledge by testing the regression coefficients for condition at one standard deviation below (lower prior knowledge) and above (higher prior knowledge) the mean in models with condition coded as 0 for continuous and 1 for segmented (Aiken \& West, 1991).

The regression models for performance on near and far transfer were both significant, near: $F(3,71)=8.61, p=.00$, adjusted $R^{2}=.24$; far: $F(3,71)=6.01, p=.00$, adjusted $R^{2}=.17$. The regression coefficients for the interaction terms were not significant, however.

The regression model for mental effort during instruction was marginally significant, $F(3,71)=2.57, p=.06$, adjusted $R^{2}=.06$, and the regression coefficient for the interaction term was significant, $\beta=0.38, t(71)=2.06, p=.04$. Fig. 2 depicts the interaction between prior knowledge and condition on mental effort during instruction. At one standard deviation below the mean the difference in mental effort invested in studying continuous, animated examples was marginally higher than in studying segmented ones, $\beta=-0.32, t(71)=-1.98, p=.05$. With higher levels of prior knowledge, the mental effort invested in studying continuous, animated examples decreased, $\beta=-0.49, t(71)=-2.71, p=.01$, whereas for segmented examples this remained almost equal, $\beta=-0.02$, $t(71)=-0.11, p=.91$. Consequently, no significant difference was found in the mental effort invested in studying continuous and segmented animated examples at one standard deviation above the mean, $\beta=0.16, t(71)=0.98, p=.33$.

The regression models for instructional efficiency on near and far transfer were both significant, near: $F(3,71)=7.13, p=.00$, adjusted $R^{2}=.20$; far: $F(3,71)=6.70, p=.00$, adjusted $R^{2}=.19$, and so were the regression coefficients for the interaction term, near: $\beta=-0.35, t(71)=-2.07, p=.04 ;$ far: $\beta=-0.34, t(71)=-2.00$, $p=.05$. Fig. 3 depicts the interactions between prior knowledge 


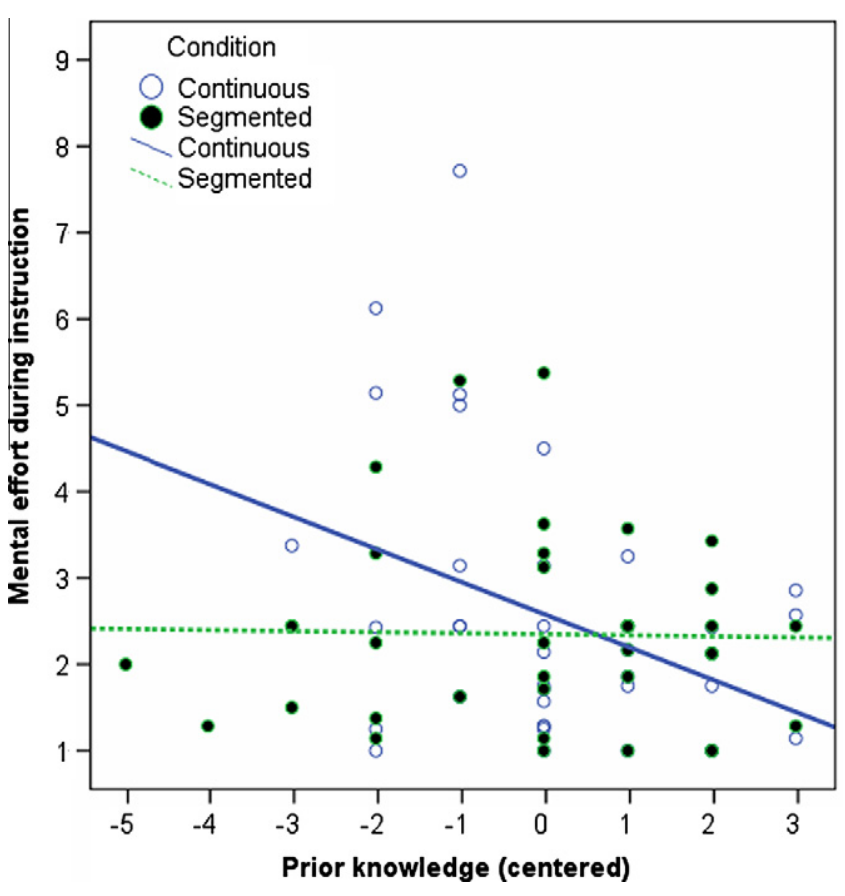

Fig. 2. The interaction between prior knowledge (centered) and condition on mental effort during instruction.

and condition on near and far transfer. It shows that at one standard deviation below the mean segmented, animated examples were more efficient than continuous ones, near $\beta=0.39, t(71)=2.60$, $p=.01$, far: $\beta=0.33, t(71)=2.20, p=.03$. With higher levels of prior knowledge, the efficiency of continuous, animated examples increased significantly, near: $\beta=0.68, t(71)=4.04, p=.00$, far: $\beta=$ $0.68, t(71)=4.00, p=.00$, whereas the efficiency of segmented, animated examples increased more slowly and only marginally significant, near: $\beta=0.24, t(71)=1.79, p=.08$, far: $\beta=.25, t(71)=$ $1.85, p=.07$. As a consequence, the difference in efficiency between the two conditions had disappeared at one standard deviation above the mean, near: $\beta=-0.05, t(71)=-0.36, p=.72$, far: $\beta=-0.10$, $t(71)=-0.67, p=.51$.

\section{Discussion}

In line with our hypothesis, the results showed an expertise reversal effect of segmentation in terms of efficiency: For students with lower levels of prior knowledge segmented, animated worked-out examples were more efficient than continuous, animated worked-out examples, that is, they attained equal performance with less investment of mental effort during learning. However, the superiority of segmented, animated worked-out examples disappeared at higher levels of prior knowledge. This suggests that only for students with lower levels of prior knowledge, segmentation successfully reduces the high cognitive load imposed by animations and leads to more efficient learning.

The positive effect of segmentation with lower levels of prior knowledge and its disappearance at higher levels of prior knowledge is mainly driven by differences in mental effort investment by students with different levels of prior knowledge. With regard to performance, no significant differences were found between the conditions in the increase of scores with higher levels of prior knowledge. Possibly, this is a consequence of the range of prior knowledge of participants in our study: most of them were not complete novices or full experts in the domain of probability calculation, so although there were differences in prior knowledge, these did not span the entire continuum. This may explain why we did not find an interaction of segmentation and prior knowledge on performance, but only on mental effort and efficiency, which constitute more subtle measures of differences in learning processes and outcomes between (groups of) participants (Van Gog \& Paas, 2008). Future studies might examine whether a broader range of prior knowledge would lead to an interaction effect on performance, and whether such a broader range might lead not only to a disappearance of benefits of segmentation, but to a complete reversal of effects, with continuous animations being more effective than segmented ones at high levels of prior knowledge.

As mentioned in the introduction, there are two possible (not mutually exclusive) explanations for the effectiveness of
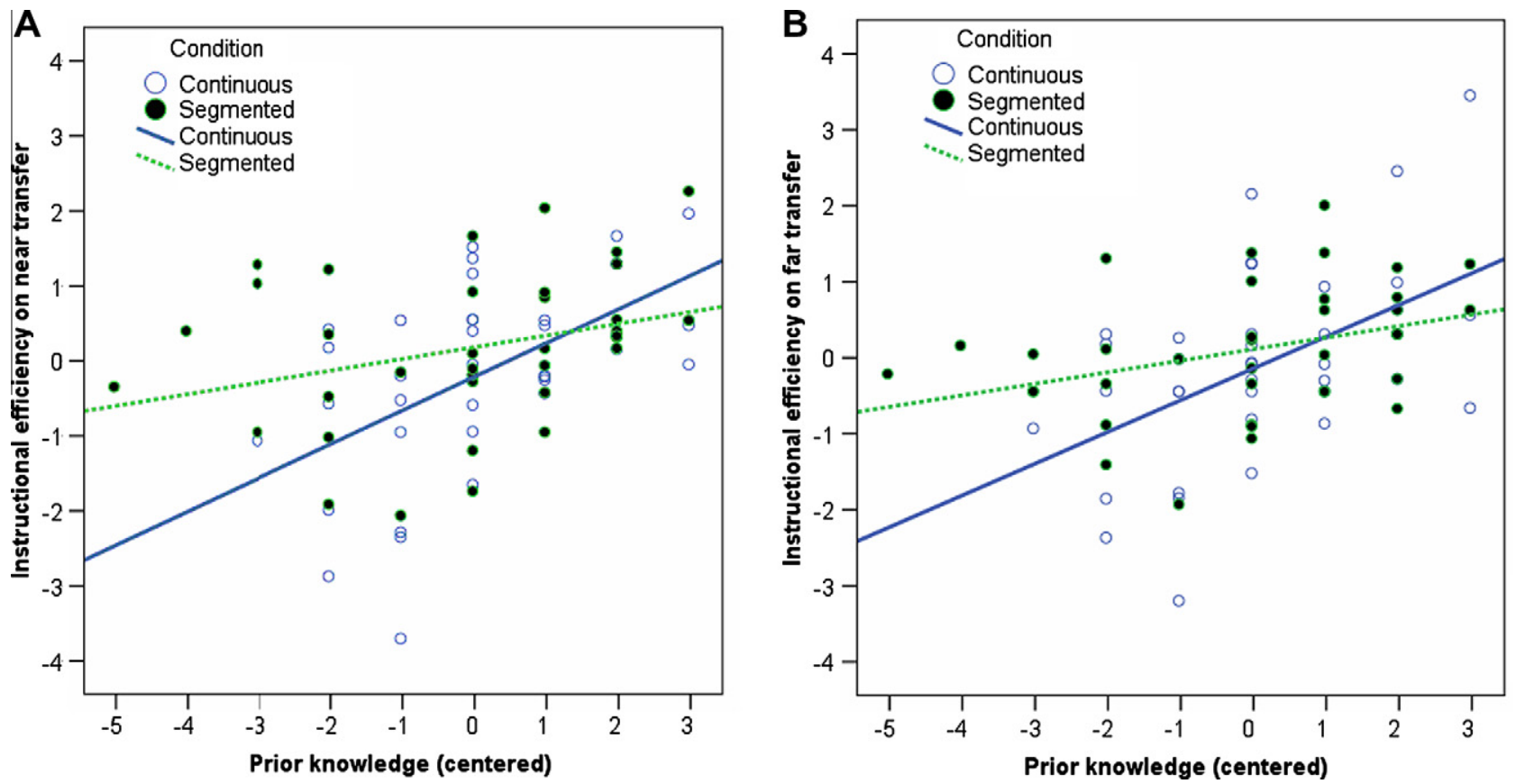

Fig. 3. The interaction between prior knowledge (centered) and condition on instructional efficiency for near (A) and far transfer (B). 
segmentation for students with lower levels of prior knowledge. First, segmentation as implemented in this and other studies may be effective, because there are pauses between segments, which gives students additional time to process the information presented (Mayer \& Moreno, 2003). Secondly, segmentation breaks the animation down into meaningful pieces (Schnotz \& Lowe, 2008), which may aid students by distinguishing the events or sub-steps in a process/procedure and - possibly - stimulating them to self-explain the structure of the process/procedure and the goals of those events or sub-steps (cf. Catrambone, 1998). However, which of these explanations is more plausible, or whether it is the combination of pausing and indicating the problem structure that makes segmenting effective for students with lower levels of prior knowledge, is an open question for future research to address.

A possible limitation of this study was that the pauses between segments led to a difference in learning time between the conditions: students in the segmented condition had more time for each animated example than students in the continuous condition. Note though, that during these pauses no additional information was provided (only the last frame of the previous segment was visible), and that $2 \mathrm{~s}$ is probably too short for processes such as reflection. In addition, it is questionable whether increasing learning time without temporarily suspending incoming information at meaningful intervals would be effective. In other words, pausing at meaningful intervals provides a more specific explanation for the effectiveness of segmentation for learners with low prior knowledge than increasing learning time in general, because it only predicts positive effects of inserting time periods without incoming information at particular places and not of other ways to increase learning time. Nevertheless, differences in time-on-task between conditions should be controlled in future studies in order to rule out this alternative explanation.

In addition, this study did not provide any clues as to what cognitive processes lead to the expertise reversal effect. Are advanced students hindered by the pauses? Or by the locations of the segments, which might interfere with the sub-steps indicated in their acquired problem solution schemas? Therefore, future studies should try to uncover the cognitive processes taking place during the studying of animations by students with lower and higher levels of prior knowledge. This can be done using verbal reports (Ericsson \& Simon, 1993), but given that animations often contain spoken text, thinking aloud during animation study is not a viable option. Cued retrospective reporting, that is, having students report retrospectively what they thought during studying the animations supported by a replay of the animations combined with a record of their eye movements (Van Gog, Paas, Van Merriënboer, \& Witte, 2005) seems to be a good alternative and has been used in several studies on learning from animations and videos (De Koning, Tabbers, Rikers, \& Paas, 2010; Jarodzka, Scheiter, Gerjets, \& Van Gog, 2010).

Finally, an interesting question for future research is whether the expertise reversal effect of segmentation also applies to animations with different learning content. In this experiment, students acquired problem solving knowledge from the animated examples. It is unclear whether the results can be generalised to animations from which students have to acquire declarative knowledge about natural processes or mechanical systems.

In sum, this study provides some evidence that an expertise reversal effect of segmentation in animated worked-out examples occurs. Designers should, therefore, take prior knowledge of students into account when developing instructional animations, and implement measures such as segmentation to reduce the high cognitive load imposed by the transience of animations for students with lower levels of prior knowledge, but not for students with higher levels of prior knowledge.

\section{References}

Aiken, L. S., \& West, S. G. (1991). Multiple regression: Testing and interpreting interactions. Newbury Park, CA: Sage.

Amadieu, F., Mariné, C., \& Laimay, C. (2011). The attention-guiding effect and cognitive load in the comprehension of animations. Computers in Human Behavior, 27, 36-40.

Ayres, P., \& Paas, F. (2007). Can the cognitive load approach make instructional animations more effective? Applied Cognitive Psychology, 6, 811-820.

Baddeley, A. (2003). Working memory: Looking back and looking forward. Nature Reviews: Neuroscience, 4, 828-839.

Barrouillet, P., \& Camos, V. (2007). The time-based resource-sharing model of working memory. In N. Osaka, R. H. Logie, \& D. E. Mark (Eds.), The cognitive neuroscience of working memory (pp. 57-80). Oxford: Oxford University Press.

Catrambone, R. (1998). The subgoal learning model: Creating better examples so that students can solve novel problems. Journal of Experimental Psychology: General, 127, 335-376.

Chandler, P. (2009). Dynamic visualizations and hypermedia: Beyond the 'Wow' factor. Computers in Human Behavior, 25, 389-392.

De Koning, B. B., Tabbers, H. K., Rikers, R. M. J. P., \& Paas, F. (2007). Attention cueing as a means to enhance learning from an animation. Applied Cognitive Psychology, 21, 731-746.

De Koning, B. B., Tabbers, H. K., Rikers, R. M. J. P., \& Paas, F. (2010). Attention guidance in learning from a complex animation: Seeing is understanding? Learning and Instruction, 20, 111-122.

Ericsson, K. A., \& Simon, H. A. (1993). Protocol analysis: Verbal reports as data (Rev. ed.). Cambridge, MA: MIT Press.

Hegarty, M., Kriz, S., \& Cate, C. (2003). The roles of mental animation and external animation in understanding mechanical systems. Cognition and Instruction, 21, 325-360.

Höffler, T. N., \& Leutner, D. (2007). Instructional animation versus static pictures: A meta-analysis. Learning and Instruction, 17, 722-738.

Jarodzka, H., Scheiter, K., Gerjets, P., \& Van Gog, T. (2010). In the eyes of the beholder: How experts and novices interpret dynamic stimuli. Learning and Instruction, 20, 146-154.

Kalyuga, S. (2008). Relative effectiveness of animated and static diagrams: An effect of learner prior knowledge. Computers in Human Behavior, 24, 852-861.

Kalyuga, S., Ayres, P., Chandler, P., \& Sweller, J. (2003). The expertise reversal effect. Educational Psychologist, 38, 23-31.

Macromedia. (2002). Flash $M X^{\mathrm{TM}}$ [Computer software]. San Francisco, CA: Macromedia.

Mayer, R. E., \& Chandler, P. (2001). When learning is just a click away: Does simple user interaction foster deeper understanding of multimedia messages? Journal of Educational Psychology, 93, 390-397.

Mayer, R. E., Hegarty, M., Mayer, S., \& Campbell, J. (2005). When static media promotes active learning: Annotated illustrations versus narrated animations in multimedia instruction. Journal of Experimental Psychology: Applied, 11, 256-265.

Mayer, R. E., Mathias, A., \& Wetzell, K. (2002). Fostering understanding of multimedia messages through pre-training: Evidence for a two-stage theory of mental model construction. Journal of Experimental Psychology: Applied, 8, $147-154$.

Mayer, R. E., \& Moreno, R. (2003). Nine ways to reduce cognitive load in multimedia learning. Educational Psychologist, 38, 43-52.

Paas, F. (1992). Training strategies for attaining transfer of problem-solving skill in statistics: A cognitive-load approach. Journal of Educational Psychology, 84, 429-434.

Paas, F., \& Van Merriënboer, J. J. G. (1993). The efficiency of instructional conditions: An approach to combine mental effort and performance measures. Human Factors, 35, 737-743.

Schmidt-Weigand, F., \& Scheiter, K. (2011). The role of spatial descriptions in learning from multimedia. Computers in Human Behavior, 27, 22-28.

Schnotz, W. (2002). Enabling, facilitating and inhibiting effects in learning from animated pictures. Paper presented at the International Workshop on Dynamic Visualizations and Learning, Tübingen, Germany. Downloaded on 31 July 2008 from http://www.iwm-kmrc.de/workshops/visualization/schnotz.pdf.

Schnotz, W., \& Lowe, R. (2008). A unified view of learning from animated and static graphics. In R. Lowe \& W. Schnotz (Eds.), Learning with animations: Research implications for design (pp. 304-356). Cambridge, MA: Cambridge University Press.

Sweller, J., Van Merriënboer, J. J. G., \& Paas, F. (1998). Cognitive architecture and instructional design. Educational Psychology Review, 10, 251-296.

Tversky, B., Heiser, J., Mackenzie, R., Lozano, S., \& Morrison, J. (2008). Enriching animations. In R. Lowe \& W. Schnotz (Eds.), Learning with animations: Research implications for design (pp. 263-285). Cambridge, MA: Cambridge University Press.

Tversky, B., Morrison, J. B., \& Betrancourt, M. (2002). Animation: Can it facilitate? International Journal of Human-Computer Studies, 57, 247-262.

Van Gog, T., \& Paas, F. (2008). Instructional efficiency: Revisiting the original construct in educational research. Educational Psychologist, 43, 16-26.

Van Gog, T., Paas, F., Marcus, N., Ayres, P., \& Sweller, J. (2009). The mirror neuron system and observational learning: Implications for the effectiveness of dynamic visualizations. Educational Psychology Review, 21, 21-30.

Van Gog, T., Paas, F., Van Merriënboer, J. J. G., \& Witte, P. (2005). Uncovering the problem-solving process: Cued retrospective reporting versus concurrent and 
retrospective reporting. Journal of Experimental Psychology: Applied, 11, 237-244.

Van Merriënboer, J. J. G., \& Sweller, J. (2005). Cognitive load theory and complex learning: Recent developments and future directions. Educational Psychology Review, 17, 147-177.

Wetzels, S. A. J., Kester, L., \& Van Merriënboer, J. J. G. (2011). Adapting prior knowledge activation: Mobilisation, perspective taking, and learners' prior knowledge. Computers in Human Behavior, 27, 16-21.
Wouters, P., Paas, F., \& Van Merriënboer, J. J. G. (2009). Observational learning from animated models: Effects of modality and reflection on transfer. Contemporary Educational Psychology, 34, 1-8.

Wouters, P., Paas, F., \& Van Merriënboer, J. J. G. (2010). Observational learning from animated models: Effects of studying-practicing alternation and illusion of control on transfer. Instructional Science, 38, 89-104. 